\title{
GEOLOGIA DA FOLHA DE SÃO JOÃO DA BOA VISTA
}

\author{
LIDIA KEIKO TOMINAGA * \\ RESUMO
}

Na Folha de São João da Boa Vista, ocorrem rochas do Grupo Pinhal de idade pré-cambriana superior, representadas por um complexo migmatítico-granítico, e rochas sedimentares do Grupo Itararé de idade carbonífero superior a permiano inferior, constituídas por arenitos, siltitos e diamictitos.

Ocorrem também, uma pequena intrusão alcalina (tinguaito) e vários corpos de diabásio sob forma de "sills" e diques.

A cobertura cenozóica é aqui dividida em dois tipos, de acordo com as prováveis épocas de deposição: Terciário e Quaternário.

O Terciário é caracterizado por sedimentos areno-argilosos inconsolidados que ocorrem formando colinas de encostas convexas, com espessuras da ordem de 10 a $15 \mathrm{~m}$ e o Quaternário representado por depósitos aluviais associados às linhas de drenagens atuais.

\section{ABSTRACT}

In São João da Boa Vista topographic sheet occur Pinhal Group (upper Pre-Cambrian (formed by migmatite-granites complex, and Itararé Group (upper Carboniferous - lower Permian) made up by sandstones, siltstones and diamictites.

Small alkali intrusion (tinguaite) and diabases sills and dikes are also present.

The cenozoic sediments belong about two different depositional periods: Tertiary and Quaternary. The first one is characterized by unconsolidated sediments (sands and muds) most of them covering the hills. The least is represented by alluvial deposits on river terraces.

\section{INTRODUÇÃO}

Este trabalho de cunho geológico, constitui parte do "Projeto de Levantamento Geológico de Formações Superficiais", cuja área de estudo, localiza-se na porção Centro-Nordeste do Estado de São Paulo, abrangendo a follha topográfica de São João da Boa Vista, na escala de 1:50.000, na qual se encontram rochas sedimentares e metamórficas, além de intrusivas básicas.

Tem como objetivo a caracterização das unidades geológicas e sua representação cartográfica.
Localização e Vias de Acesso: A área mapeada abrange a folha topográfica de São João da Boa Vista, na escala de 1:50.000, editada pelo IBGE (SF. 23-V-C-VI-3) em 1972, cobrindo uma área de aproximadamente $715 \mathrm{Km}^{2}$. Situa-se na região centronordeste do Estado de São Paulo, entre os paralelos $21^{\circ} 45^{\prime}$ e' $22^{\circ} 00^{\prime}$ Sul e os meridianos $46^{\circ} 45^{\prime}$ e $47^{\circ} 00^{\prime}$ a Oeste de Greenwich tendo como principais centros urbanos, as cidades de São João da Boa Vista e Vargem Grande do Sul.

Suas principais vias de acesso são: as rodovias $\mathrm{SP}-344$ e $\mathrm{SP}-340$ que in-

* Geólogo - Seção de Estudos Geológicos - Instituto Geológico. 
terligam os municípios de Aguaí, São João da Boa Vista, Vargem Grande do Sul e Caconde.

Trabalhos Prévios: São numerosos os estudos relacionados à geologia da região nordeste e leste paulista e sul de Minas Gerais, que abrangem a área de São João da Boa Vista. Na parte do Pré-Cambriano destacam-se os seguintes:

EBERT (1968), realizou estudos na região sul de Minas Gerais e adjacências, dividindo a área estrutural, metamórfica e estratigraficamente. A divisão estratigráfica proposta compreende três grupos de idade pré-cambriana superior: Paraíba, Andrelândia e São João Del Rey. Estruturalmente, - Grupo Paraíba corresponde aos "internides" e os Grupos Andrelândia, São João Del Rey e ainda partes do Paraíba aos "externides" de uma grande faixa orogênica de idade pré-cambriana superior que se amolda em torno do Craton de São Francisco.

Esse mesmo autor (1968, 1971, 1974), correlacionou essas unidades criadas com as caracterizadas posteriormente em São Paulo, elaborando um mapa geológico-estrutural do sul de Minas Gerais e leste do Estado de São Paulo.

WERNICK (1978a), dividiu o PréCambriano do leste do Estado de São Paulo e áreas vizinhas nas seguintes unidades: Grupo Amparo, de idade Transamazônica, que corresponderia ao Grupo Paraíba englobando os Grupos Andrelândia e Itapira; Grupo Pinhal de idade Brasiliana; Formações Eleutério e Pouso Alegre, também de idade Brasiliana e definiu o Grupo Pinhal como uma unidade migmatíticagranítica, resultante da profusa intrusão de granitos em rochas do Grupo Amparo.

Estudando ainda, (1978b), os grupos acima mencionados, descreve a estrutura dos complexos graníticosmigmatíticos, constantando uma evolução estrutural policíclica para o ma- ciço de Guaxupé, com várias fases atribuídas ao Pré-Cambriano Médio, ao Pré-Cambriano Superior e ao Fanerozóico.

Com relação aos sedimentos da $\mathrm{Ba}$ cia do Paraná destacam-se os seguintes trabalhos:

PETRI (1964), propõe o agrupamento de todo o complexo glacial do Grupo Tubarão, constituídos por arenitos, siltitos, tilitos, varvitos, argilitos, conglomerados e calcários sob a denominação Subgrupo Itararé e, Tatuí para os arenitos finos e siltitos pós-glaciais.

LANDIM (1973), emprega o termo Formação Itararé, para o ciclo glacial do Grupo Tubarão, constituído por arenitos, siltitos, ritmitos, mistitos e camadas centimétricas de carvão. Admite, porém, que ela venha ser desmembrada em outras formações com o desenvolvimento dos estudos.

SOARES et alii (1973), estudando a região nordeste do Estado de São Paulo, descrevem na área, o PermoCarbonífero, o Mesozóico e Cenozóico. Utilizam a designação Formação Aquidauana para os arenitos, lamitos e diamictitos de idade carbonífero superior a permiano inferior, contemporâneos aos da Formação Itararé.

BRASIL-DNPM (1979) - Projeto Sapucaí, adota definições de MUHLMAN et alii, elevando o termo Grupo Tubarão para a categoria de Supergrupo Tubarão, dividindo-o nos Grupos Itararé e Guatá. O Grupo Itararé permanece indiviso no Estado de São Paulo, sendo caracterizados na área deste Projeto, por sedimentos essencialmente arenosos, de granulometria variável, com diamictitos de cor vermelho-tijolo.

Metodologia: Foi executada pesquisa bibliográfica e levantamento aerofotogeológico preliminar da área, em fotografias aéreas na escala de $1: 25.000$, levantadas pelo IBC GERCA em 1971. 
Os trabalhos de campo tiveram como base, a folha topográfica de São João da Boa Vista, na escala de $1: 50.000$, e consistiram em observaçõe e descrição de afloramentos, estruturas, texturas, contatos, etc., com coleta de amostras para análises granulométricas e petrográficas.

A partir dos dados coletados no campo, acrescidos ainda, de uma fotointerpretação geológica e de análises granulométricas e petrográficas, foi possível organizar o mapa geológico.

\section{ASPECTOS GEOGRÁFICOS}

Devido a variação topográfica da área de São João da Boa Vista, de relevo suave a muito acidentado, com altitudes de 600 a $1.400 \mathrm{~m}$, seu comportamento térmico enquadra-se' no tipo Tropical, mas com duas categorias climáticas: subquente e mesotérmico brando NIMER (1977). As temperaturas médias anuais variam, respectivamente de 20 a $22^{\circ} \mathrm{C}$ e de 18 a $20^{\circ} \mathrm{C}$.

Da mesma forma que ocorrem dois tipos de relevos e duas categorias climáticas, também a vegetação apresenta duas formações distintas: Florestas Subcaducifólia Tropical e Cerrado (ALONSO 1977). Estas formações vegetais são as primitivas, das quais pouco restam. Sua fisionomia foi sendo alterada, conservando-se apenas poucos remanescentes, pois essa região foi intensamente ocupada pelo homem.

No aspecto topográfico a área, em questão, apresenta grande heterogeneidade, devido a diversidade de rochas ocorrentes.

As rochas cristalinas do Pré-Cambriano, ocupando quase dois terços da área, enquadra-se numa zona de transição entre as terras altas do sudoeste mineiro e a região rebaixada da Depressão Periférica. Forman dois tipos de relevo: um acentuado com morros arredondados e pouco íngremes, cortados por densa drenagem, altitudes variando de 700 a aproximada- mente $850 \mathrm{~m}$, ocorrendo principalmente numa faixa de direção NW, ao longo do contato com a Bacia do Paraná e nas imediações da cidade de São João da Boa Vista.

O segundo tipo ocupa principalmente a parte $\mathrm{E}-\mathrm{NE}$ da folha, formando morros muito acidentados e escarpas íngremes nas serras da Fartura e da Forquilha, atingindo cotas de até $1.400 \mathrm{~m}$, e apresenta alta densidade de drenagem.

No lado Oeste da folha, ocupado pelos sedimentos do Grupo Itararé e Cenozóico, desenvolveu-se um relevo suave com predominância de densidade de drenagem média e subordinadamente baixa, com cotas variando de 600 a $700 \mathrm{~m}$. Áreas mais planas, com densidade de drenagem muito baixa, são formadas pelos depósitos cenozói$\cos$.

Destacam-se na superfície suavizada dos sedimentos, as intrusivas básicas suistentando um relevo mais saliente com altitudes de até $870 \mathrm{~m}$.

$\mathrm{Na}$ divisão germorfológica do Estado de São Paulo, a área ocupada pelas rochas cristalinas enquadra-se na Zona Cristalina da Província do Planalto Atlântico e a parte das rochas sedimentares, na Zona Mogi-Guaçu da Província da Depressão Periférica (ALMEIDA, 1964).

A bacia hidrográfica da área é formada pelo rio Jaguari Mirim, principal afluente do rio Mogi Guaçu, destacando-se ainda, o rio Verde e o Ribeirão dos Porcos que correm ao longo do contato das rochas pré-cambrianas com as da bacia do Paraná.

ESTRATIGRAFIA: Na parte Leste da folha de São João da Boa Vista ocorrem rochas pré-cambrianas, representadas principalmente por migmatitos. O lado Oeste é ocupado por sedimentos do Grupo Itararé, Super-Grupo Tubarão, de idade permo-carbonífera, constituídos, essencialmente de arenitos, siltitos e diamictitos. A cobertura 
cenozóica caracterizada por sedimentos arenosos e/ou argilosos inconsolidados, capeando partes do Grupo Itararé e das rochas pré-cambrianas, têm maior expressão na parte Oeste - Noroeste da folha. Os aluviões recentes ocorrem associados à rede hidrográfica.

\section{PRÉ CAMBRIANO}

As rochas pré-cambrianas são constituídas por um complexo migmatíco-granítico denominado Grupo Pinhal, resultante da profusa intrusão de granitos, durante o ciclo Brasiliano, em rochas do Grupo Amparo de idade Transamazônica, WERNICK (1978a).

O Grupo Pinhal é constituído, principalmente, por rochas migmatíticas e granitóides, WERNICK e PENALVA (1980), que se encontram intrinsecamente associadas. Os termos granitóides englobam granitos equigranulares e porfiróides. Os equigranulares com granulação variando de fina a grossa, localmente com textura pegmatóide, são de coloração cinzenta, rósea ou esbranquiçada. Apresentam, com frequência, gnaissificação incipiente. Nos porfiróides, os fenocristais predominantes são de microclina e' secundariamente de oligoclásio, com formas retangulares, ovaladas ou irregulares, de cores cinzenta ou rosada, com tamanhos variando, mais frequentemente, de 3 a $6 \mathrm{~cm}$. Em geral. estes fenocristais encontram-se fracamente orientados. A matriz tem também cores cinzenta e rosada e' sua granulação varia de fina a grossa.

Os granitos equigranulares e a matriz dos granitos porfiróides são compostos principalmente por quantidades variáveis de quartzo, plagioclásio, microclina e máficos. O quartzo apresenta-se sob forma anhedral, exibindo com frequência extinção ondulante, ocupa posição intersticial e às vezes constitui megacristais. O plagioclásio, de forma subhedral com geminação polissintética que frequente- mente, predomina sobre a microclina, é representado por oligoclásio ou andesina.

Quando a rocha é mais rica em plagioclásio, a microclina ocorre sob forma anhedral preenchendo os interstícios. Se a microclina é predominante, pode assumir formas subhedral nos megacristais e anhedral nos cristais menores da matriz, exibindo geminação em grade.

Os máficos estão representados, principalmente por biotita e hornblenda. A biotita de cor marrom clara apresenta forma lamelar com bordas mais ou menos irregulares, podendo ocorrer cloritização nos bordos. A hornblenda de cor marrom esverdeada aparece sob forma colunar e/ou irregular. A composição destas rochas granitóides varia de quartzo-diorítica a granítica (WERNICK e PENALVA op. cit.).

Os migmatitos são de core cin- $_{S}$ zenta e rosada, exibindo estruturas "Schlieren", "Schollen", nebulítica, oftalmítica e, menos frequentemente, acamada. Nesses migmatitos predomina o neossoma sobre o paleossoma que se apresenta difuso, entretanto. encontram-se leitos de paleossoma, em geral, constituídos por biotita-gnaisse, com espessuras desde centimétricas, até $1 \mathrm{~m}$, como se observa na pedreira a $2 \mathrm{Km}$ a Sudeste de São João da Boa Vista.

Estes migmatitos são complexos e polifásicos, resultantes da interferência de auréolas migmatíticas contíguas, (WERNICK e PENALVA op. cit.).

A $16 \mathrm{Km}$ a Leste de Vargem Grande do Sul em corte da estrada que liga esta cidade a São Roque da Fartura, foi encontrado akerito, já ćescrito por FREITAS (1956). Macroscópicamente, o akerito apresenta cor cinza esverdeada, estrutura compacta, com cristais de feldspato de tamanhos variáveis de $0,5 \mathrm{~mm}$ a $2 \mathrm{~cm}$. São visíveis, também quartzo granular de cor cinzenta de tamanhos milimétricos. Ao 
microscópio, exibe entrelaçamento hipidiomórfico e textura micrográfica. Esta rocha contém, como componentes essenciais: ortoclásio micropertítico, oligoclásio, quartzo, alanita, barkevicita (hornblenda), mirmequita e clorita; como acessórios, contém magnetita, apatita, zircão e turmalina (lâmina descrita pelo prof. Dr. Ruy Ozório de Freitas).

As rochas do Grupo Pinhal acham se cortadas por pequenos veios de quartzo e de pegmatitos com espessuras centimétricas a decimétricas.

A gnaissificação é mais evidente nos migmatitos, enquanto que nos granitos porfiróides e equigranulares é incipiente. Apresenta predominantemente, um sistema noroeste, com direções variando de $\mathrm{N} 15^{\circ}-40^{\circ} \mathrm{W}$ e $\mathrm{N} 65^{\circ}-75^{\circ} \mathrm{W}$ e mergulhos de $30^{\circ}-$ $60^{\circ} \mathrm{SW}$ e subordinadamente um sistema nordeste, com direçõe ${ }_{S}$ de $\mathrm{N} 50^{\circ}$ $-80^{\circ} \mathrm{E}$ e mergulhos de $45^{\circ} \mathrm{SE}$ e subvertical.

As rochas do Grupo Pinhal se situam na parte leste desta folha, ocupando aproximadamente dois terços da área. Afloram sob forma de matacões ou em cortes de estradas, sendo melhor expostas em duas pedreiras, uma localizada na Faz. Paulopéia a $1,5 \mathrm{Km}$ a noroeste de São João da Boa Vista e outra a $2 \mathrm{Km}$ a sudeste da mesma cidade.

O contato entre as rochas migmatíticas e granitóides é extremamente difuso, pois estas ocorrem intimamente associadas. $\mathrm{O}$ akerito permite uma individualização aproximada das rochas migmatíticas e graníticas. O contato do Grupo Pinhal com a bacia sedimentar do Paraná, faz-se através de uma superfície erosiva e irregular, como o verificado em afloramento a 6 $\mathrm{Km}$ a oeste de São João da Boa Vista, ao longo da estrada que liga esta cidade ao Bairro Cantagalo, estando no restante da área, encoberto pelos solos residuais e/ou coluviais e pelos sedimentos cenozóicos.
A idade do complexo graníticomigmatítico do Grupo Pinhal . conforme WERNICK (1978a e 1980), é referível às várias fase's do ciclo Brasiliano $(500-650 \mathrm{~m}$.a. $)$.

\section{GRUPO ITARARÉ}

É caracterizado por sedimentos essencialmente arenosos, siltitos e diamictitos de cor vermelho-tijolo. É possível que se trate da Formação Aquidauana, inicialmente descrita como "Série Aquidauana" por ALMEIDA (1954) e BEURLEN (1956) na borda oeste da bacia do Paraná.

SOARES et alii (1973) empregaram o termo, Formação Aquidauana para os sedimentos semelhantes aos acima citados, ocorrentes na região nordeste do Estado de São Paulo.

Estudando as regiões de Araras, Conchal e Mogi Guaçu, SOARES e LANDIM (1973) constataram sedimentos avermelhados da Formação Aquidauana interdigitados com os da Fm Itararé de coloração acinzentada.

Os sedimentos, presumivelmente da Fm Aquidauana constituem-se, principalmente, de arenitos e siltitos marrom avermelhados e, subordinadamente de diamictito ${ }_{S}$ e argilitos da mesma coloração. Encontram-se nos arenitos, lâminas de coloração esbranquiçadas e arroxeadas. e muito raramente acizentadas.

A granulometria dos arenitos varia de muito fina a grossa, predominando a fração fina a média, pobremente a muito pobremente selecionados, com abundante matriz síltico-argilosa.

$\mathrm{O}_{\mathrm{S}}$ arenitos apresentam-se em corpos tabulares com estratificação plano paralela, estratificação cruzada planar e tangencial na base, de pequeno porte e algumas vezes, micro estratificação cruzada e em bancos maciços. Contém ocasionalmente, pequenas intercalações de camadas e lentes de 
siltitos de espessura muito variáveis, menores que $0,50 \mathrm{~m}$, como observado próximo ao Córrego Bela Vista a Sudoeste da folha.

Os siltitos são predominantemente argilosos, menos frequentemente podem ser arenosos. A cor marrom avermelhada é dominante, apresentando por vezes manchas ou faixas esbranquiçadas por efeitos epigenéticos. Ocorrem em bancos maciços e, às vezes, com laminação incipiente. Em geral, encontram-se intensamente fraturados, tornando-se friáveis. É comum a presença de pequenas lentes e lâminas de areia nos siltitos.

Os diamictitos são menos frequentes aflorando somente na porção SulSudoeste. Contém principalmente seixos e as vezes blocos $_{S}$ em pequena proporção, em geral de 5 a $10 \%$. Os seixos em geral, são alongados e apresentamse subarredondados, de constituição, predominantemente quartzítica, granítica e subordinadamente de outras rochas metamórficas e sedimentares. A matriz é lamítica de cor marrom avermelhada contendo grânulos angulosos de quartzo. Os diamictitos exibem, às vezes uma laminação incipiente, mas não apresentam acamamento e raramente podem conter níveis ou pequenas lentes arenosas.

A Formação Aquidauana ocorre no lado Oeste da Folha, ocupando em superfície, cerca de um quarto da área total estudada.

Na parte Norte da área, o contato entre a Formação Aquidauana e as rochas cristalinas, acha-se encoberto por sedimentos Cenozóicos e ao Sul o contato está mascarado pela presença de um espesso "sili" de diabásio (vide mapa geológico anexo).

O contato direto da Fm Aquidauana com o cristalino foi verificado somente em um afloramento, a $6 \mathrm{Km}$ a Oeste de São João da Boa Vista, na estrada que liga esta cidade ao Bairro do Cantagalo, no qual o diamictito assenta-se sobre rocha alterada do préCambriano, através de uma superfície erosiva e irregular. Numa pequena área mais a sul deste afloramento, o contato está encoberto por solos residuais e/ou coluviais.

DAEMON e QUADROS (1970) estabeleceram a idade da Fm Aquidauana como sendo Carbonífero Superior. SOARES (1972) verificou a contemporaneiedade do Aquidauana com as fácies Superiores do Itararé do Permiano inferior.

$\mathrm{O}$ ambiente de deposição da $\mathrm{Fm}$ Aquidauana é continental, predominantemente fluvial, com depósitos de canalı e transbordamento.

Os diamictitos, podem ser resultantes do retrabalhamento de depósitos glaciais por rios, torrente ${ }_{S}$ e corridas de lama, conservando uma pequena proporção de seixos em relação à matriz lamítica ou arenosa. A coloração avermelhada indica a condição oxidante do processo sedimentar a que foi submetido esse material (SOARES et alii, 1973).

\section{CENOZÓICO}

Os sedimentos cenozóicos situamse principalmente na parte Oeste da área, onde o relevo é mais suave e rebaixado. Estes sedimentos são aqui divididos em Terciário e Quaternário.

O Terciário constitui-se de sedimentos areno-argilosos de coloração predominantemente avermelhada, mal selecionados, contendo grânulos angulosos de quartzo. São inconsolidados, aparentemente desprovidos de estruturas sedimentares, apresentam-se verticalmente homogêneos, assemelhandose a solo. Frequentemente, na base desses depósitos, ocorrem linhas de seixos ou até mesmo cascalheiras de pequeno porte, constituídos de seixos e blocos predominantemente de quartzito e quartzo.

Estes sedimentos ocorrem sob a forma de amplas colinas de encostas convexas, capeando formações mais antigas, com espessura que variam de 10 a 15 metros. 
Os sedimentos Terciários a Oeste e Noroeste de Vargem Grande do Sul, apresentam fração arenosa dominante tornando-os muito porosos e permeáveis. A Sul da mesma cidade, verifica-se a predominância da fração argilosa nestes sedimentos. Na Faz. Cachoeirinha, $4 \mathrm{Km}$ a Sul de Vargem Grande do Sul, ocorre uma camada de argila branca com 3 metros de espessura, contendo moldes de folhas vegetais, os quais estão em estudo.

O Quaternário constitui-se de depósitos de areias, argilas e cascalhos, de cores marrom avermelhada e variegadas, encontrados nos vales dos rios. Ocorrem de maneira expressiva nos vales dos Rios Verde e Jaguarí-Mirim.

Rochas Intrusivas: Na folha, em estudo, são assinaladas rochas intrusivas básicas na bacia sedimentar e alcalinas no Pré-Cambriano.

$\mathrm{Na}$ região centro-sul da área, acha-se um grande "sill" de diabásio de 4 a $6 \mathrm{Km}$ de largura e aproximadamente $12 \mathrm{Km}$ de comprimento, posicionado entre a Formação Aquidauana e - Pré-Cambriano; outros de menor porte aparecem na parte centro-oeste e sudoeste. Diques de diabásio com direções $\mathrm{N} 30^{\circ} \mathrm{W}$ e $\mathrm{N} 60^{\circ} \mathrm{W}$, foram encontrados a sudoeste da área. Essas rochas básicas são de cor cinza escura e preta, com textura fanerítica, granulação fina a média e estrutura maciça. Normalmente, encontram-se alteradas formando "terra roxa".

A intrusão destas rochas básicas está associada ao Vulcanismo básico que atingiu a Bacia do Paraná durante o final do Jurássico a Cretáceo, com idades que variam de 90 a 150 milhões de anos AMARAL et alii. (1966).

A ocorrência das rochas intrusivas alcalinas restringe-se a um dique aflorando sob forma de um pequeno morro $(500 \times 800 \mathrm{~m})$ no extremo leste da folha. São representadas por tinguaito, rocha de cor cinza-escura, estrutura maciça e textura sub fanerítica. Este dique alcalino está associado à intrusão alcalina de Poços de Caldas, cuja idade situa-se no Cretáceo superior AMARAL et alii, in CPRM (1979).

\section{GEOLOGIA ESTRUTURAL}

Grandes lineamentos fotogeológicos com direções predominantemente $\mathrm{NE}$ e subordinadamente $\mathrm{N}-\mathrm{S}, \mathrm{NW}$ e $\mathrm{E}-\mathrm{W}$, que controlam o padrão da drenagem, são visíveis na área do PréCambriano. O rio Jaguari Mirim tem seu curso fortemente controlado por essas direçõe S $_{S}$ estruturais. O Ribeirão Bonito tem seu curso alinhado na direção NE, onde se verificou a presença de rochas cataclasadas, constituindo uma zona de falha.

No extremo Sul da Folha, $6 \mathrm{Km}$ a Sudoeste de São João da Boa Vista, encontrou-se na Fm Aquidauana, uma pequena dobra simétrica com amplitude de aproximadamente $1,5 \mathrm{~m}$ e cerca de $4,0 \mathrm{~m}$ de comprimento. Essa dobra pode ser resultante de movimentação adiastrófica penecontemporânea à deposição ou de perturbações provocadas pela intrusão do "sill" de diabásio a Oeste. O mergulho das camadas da Fm Aquidauana, quando não perturbadas por intrusões, é de aproximadamente $0^{\circ} 30^{\prime}$ para W-NW. Nesta Formação não se nota a presença de fraturas relevantes.

O "sill" de diabásio encontrado na parte Centro-Sul apresenta em alguns trechos de seu limite, contatos retilíneos, porém não se observam evidências de movimentação ao longo desses planos, devido à cobertura coluvial.

\section{CONCLUSÕES}

1. $A_{S}$ rochas pré-cambrianas constituídas por migmatitos e granitóides, pertencem ao Grupo Pinhal de idade brasiliana (Pré-Cambriano superior). $\mathrm{O}_{\mathrm{S}}$ termos granitóides englobam granitos enquigranulares e porfiróides. O contato entre estes tipos litológicos é difuso, pois ocorrem em associação 
íntima, dificultando sua individualização.

2. Localmente, ocorrem akeritos de composição mineralógica variável entre quartzo-montonito e quartzo-soda-sienito, contendo como principal componente, ortoclásio micropertítico.

3. Os sedimentos permo-carboníferos são representados, presumivelmente, pela Formação Aquidauana, constituídos de arenitos, siltitos e diamictitos, cujo ambiente de deposição é continental, predominantemente, fluvial.

4. Os sedimentos cenozóicos (Terciário) ocupam regiõe ${ }_{S}$ de relevo suave, formando amplas colinas convexas, com espessuras pequenas (10$15 \mathrm{~m})$, capeando as formações mais antigas. Foi possível distinguir duas zonas: uma arenosa e outra argilosa.
5. A parte ocupada pelas rochas do Grupo Pinhal é a que apresenta maior número de alinhamentos estruturais representados por fraturas. Estes alinhamentos são de direções predominantemente NE e subordinadamente N-S, NW e EW.

6. Os recursos econômicos existentes, são representados pelas rochas do Grupo Pinhal e argilas do Cenozóico. A rochas do Grupo Pinhal são exploradas para uso na construção civil, sob forma de britas, em duas pedreiras, uma localizada na Faz. Paulopéia a $1,5 \mathrm{Km}$ a noroeste de São João da Boa Vista e outra a $2 \mathrm{Km}$ sudeste desta cidade. As argilas brancas do Cenozóico constituem uma ocorrência restrita na Faz. Cachoeirinha, $4 \mathrm{Km}$ a sul de Vargem Grande do Sul, sendo destinadas para o fabrico de refratários.

\section{AGRADECIMENTOS}

A autora agradece ao Prof. Dr. Ruy Osório de Freitas pela orientação concedida na execução deste trabalho. Agradece também ao geólogo Geraldo Hideo Oda, pelas críticas e sugestões apresentadas.

\section{BIBLIOGRAFIA}

ALMEIDA, F.F.M. de - 1954 - Geologia do centro-leste Mato-Grossense. Rio de Janeiro, Departamento Nacional da Produção Mineral. Divisão de Geologia e Mineralogia, 1954. 97 p. (Boletim, 50) cos do relevo paulista. In: SÃO PAULO INSTITUTO GEOGRÁFICO E GEOLÓ. GICO. Geologia do Estado de São Paulo. São Paulo. p. 169-263. (Boletim, 41).

ALONSO, IM. T. ALVES - 1977 - Vegetação. In: BRASIL. FUNDAÇÃO INSTITUTO BRASILEIRO DE GEOGRAFIA E ESTATÍSTICA. Geografia do Brasil; Região Sudeste. Rio de Janeiro. v. 3 p.91-118.

AMARAL, G. et alii - 1966 - Potassium Argon ages of basaltic rocks from Southern Brazil. Geoch. Cosmoch. Acta, Oxford, 30(2):159-189.
BEURLEN, K. - 1956 - A geologia pósalgonquiana do sul do Estado de Mato Grosso. Rio de Janeiro, Departamento Nacional da Produção Mineral. Divisão de Geologia e Mineralogia. 137 p. (Boletim, 163).

BRASIL. DEPARTAMENTO NACIONAL DA PRODUÇÃO MINERAL. - 1979 - PrOjeto Sapucaí, estados de Minas Gerais e São Paulo; relatório final de geologia. Brasília, DNPM/CPRM. 299 p. (Série Geologia, 4 - Seção Geologia Básica, 2).

DAEMON, R.F.; QUADROS L.P. - $1970-$ Bioestratigrafia do Neopaleozóico da Bacia do Paraná. In: CONGRESSO BRASILEIRO DE GEOLOGIA, 24. ${ }^{\circ}$, Brasília. Anais. Brasília, Sociedade Brasileira de Geologia. p. 359-412.

EBERT, H. - 1968 - Ocorrências da fácies' granulítica no sul de Minas Gerais e 
em áreas adjacentes, em dependência da estrutura orogênica: hipótese sôbre sua origem. An. Acad. Bras. Ciênc., Rio de Janeiro, 40:215-229. Suplemento.

1971 - Os Paraibides entre São João Del Rei, Minas Gerais e Itapira, São Paulo, e a bifurcação entre Paraibides e Araxaides. In: CONGRESSO BRASILEIRO DE GEOLOGIA, 25. São Paulo. Resumo das Comunicações. São Paulo, Sociedade Brasileira de Geologia. p. 177-178. (Boletim especial, 1). a falha de Jacutinga Nordeste de SP. In: CONGRESSO BRASILEIRO DE GEOLOGIA, 28. ${ }^{\circ}$, Porto Alegre. Resumo das Comunicações. Porto Alegre, Sociedade Brasileira de Geologia. p. 726-730. (Boletim, 1).

FREITAS, R.O. de - 1956 - Um Akerito da Serra do Mirante, S. Paulo. São Carlos, Universidade de São Paulo. Escola de Engenharia de São Carlos. 26 p. (Publicação, 6-Geologia, 1) / Separata do Boletim da Sociedade Brasileira de Geologia, 5(2) set. p. 77-90./

LANDIM, P.M.B. - 1973 - Contribuição ao estudo dos mistitos do Grupo Tubarão no Estado de São Paulo. São Carlos, Universidade de São Paulo. Escola de Engenharia de São Carlos. 198 p. (Publicação, 175 - Geologia, 17).

NIMER, E. - 1977 - Clima. In: BRASIL. INSTITUTO BRASILEIRO DE GEOGRAFIA E ESTATISTICA. Geografia do Brasil; Região Sudeste. Rio de Janeiro. v. 3 p. $51-89$.

PETRI, S. - 1964 - Grupo Tubarão. In: SÃO PAULO. INSTITUTO GEOGRÁ-
FICO E GEOLÓGICO. Geologia do Estado de São Paulo. São Paulo. p. 56-63. (Boletim, 41).

SOARES, P.C. - 1972 - O limite glacialpós glacial do Grupo Tubarão no Estado de São Paulo. An. Acad. Bras. Ciênc. Rio de Janeiro, 44:333-341. Suplemento.

et alii - 1973 - Geologia do nordeste do Estado de São Paulo. In: CONGRESSO BRASILEIRO DE GEOLOGIA, 27.0, Aracaju. Anais. Aracaju, Sociedade Brasileira de Geologia. v. 1 p. 209-228.

; LANDIM, P.M.B. - $1973-$ Aspectos regionais da estratigrafia da deste. In: CONGRESSO BRASILEIBacia do Paraná no seu flanco NorRO DE GEOLOGIA, 27.' , Aracaju. Anais. Aracaju, Sociedade Brasileira de Geologia. v. 1 p. 243-256.

- 1976 - Depósi tos Cenozóicos na região centro-sul do Brasil. Not. Geomorfol., Campinas, 16 (31):17-39.

WERNICK, E. - 1978a - Contribuição à estratigrafia do Pré-Cambriano do leste do Estado de São Paulo e áreas vizinhas. Rev. Bras'. Geoc., São Paulo, 8 (3):206-216.

- 1978b - Contribuiç̃o à geologia do Maciço de Guaxupé, SP e MG. An. Acad. Bras. Ciênc., Rio de Janeiro, 50(3):337-352.

; PENALVA. F. - 1980 - Contribuição à geologia do Grupo Pinhal, SP e MG. Rev. Bras. Geoc., São Paulo, 10(1):43-62. 